\title{
Photoelectrochemical or Electrophotochemical Processes?
}

\author{
Patricio Peralta-Zamora \\ Departamento de Química, Universidade Federal do Paraná, CP 19081, \\ 81531-990 Curitiba-PR, Brazil
}

\begin{abstract}
Nos últimos anos, muitos estudos têm relatado a eficiente degradação de substratos de relevância ambiental por processos fotoeletroquímicos, sendo que, usualmente, admite-se que o sinergismo observado entre processos foto e eletroquímicos envolve o favorecimento eletroquímico dos processos de fotocatálise. Neste trabalho, algumas evidências experimentais são discutidas, visando demonstrar que, em certas situações, o efeito sinérgico envolve conceitos diferentes, isso é, processos fundamentalmente eletroquímicos, assistidos por reações fotoquímicas subseqüentes. De acordo com as nossas observações, a elevada capacidade de degradação apresentada por eletrodos do tipo DSA na presença de eletrólitos reativos, como cloreto de sódio, é devida à geração eletroquímica de oxidantes enérgicos, como cloro molecular, os quais podem ser fotoquimicamente transformados em espécies radicalares de maior reatividade, como radical cloro. Essa suposição se mostra evidente em estudos envolvendo ácido húmico, cânfora e um corante antraquinona (azul reativo 19).
\end{abstract}

In recent years, many studies have related the efficient degradation of relevant substrates by photoelectrochemical processes. Usually, it is accepted that the synergy observed between photo and electrochemical processes involves the improvement of the photocatalytic efficiency as a result of a favorable electrochemical support. In this work some experimental observations are discussed with the aim of demonstrating that in several situations, the synergic effect involves a divergent concept. That is, an efficient electrochemical-based process assisted by subsequent photochemical reactions. As far as we know, the high degradation capacity shown by DSA electrodes used in the presence of reactive electrolytes, such us sodium chloride, is due to electrochemical generation of powerful oxidant agents, as molecular chlorine, followed by photochemical generation of active radicals, such chlorine radical. This assumption becomes clearly visible in degradation studies involving humic acid, camphor and an anthraquinone dye (reactive blue 19).

Keywords: photoelectrochemical, degradation, synergetic effect

\section{Introduction}

In recent decades, the increased seriousness of environmental problems has encouraged the development of new technologies for the treatment of wastes, among which heterogeneous catalysis stands out.

During the last twenty years, the photocatalytic degradation of environmentally relevant substrates has been extensively documented, with emphasis going to studies that report the complete degradation of recalcitrant pollutants, such as textile dyes, ${ }^{1}$ pesticides,${ }^{2}$ and polycyclic aromatic hydrocarbons, ${ }^{3}$ among others.

The principles and mechanisms involved in the heterogeneous photocatalysis process may be found

e-mail: zamora@quimica.ufpr.br in the specialized literature, among which I wish to highlight the work of Fujishima et al., ${ }^{4}$ and Gaya and Abdullah. ${ }^{5}$ To summarize, when a semiconductor (such as $\mathrm{TiO}_{2}, \mathrm{ZnO}, \mathrm{Fe}_{2} \mathrm{O}_{3}$ ) is irradiated with an energy equal to or greater than its bandgap, electrons are promoted from the valence band (VB) to the conduction band (CB), which leads to the creation of electron/hole pairs $\left(\mathrm{e}^{-} / \mathrm{h}^{+}\right)$. Although the hole in the valence band and the electron in the conduction band represent oxidation and reduction sites, capable of promoting degradation reactions, it is accepted that the main reactional path is mediated by the hydroxyl radical (HO'), which appears from the reaction between the photogenerated hole and water molecules (or hydroxyl ions) previously adsorbed on the surface of the semiconductor. To avoid the recombination of the electron/hole pair, photocatalytic processes are normally 
assisted by oxygenation. Electron capture by molecular oxygen increases the lifetime of the hole, which favors the production of the hydroxyl radical, and consequently, maximizes the degradation efficiency of the process. A diagram representing the heterogeneous photocatalysis process mediated by semiconductors is shown in Figure 1.

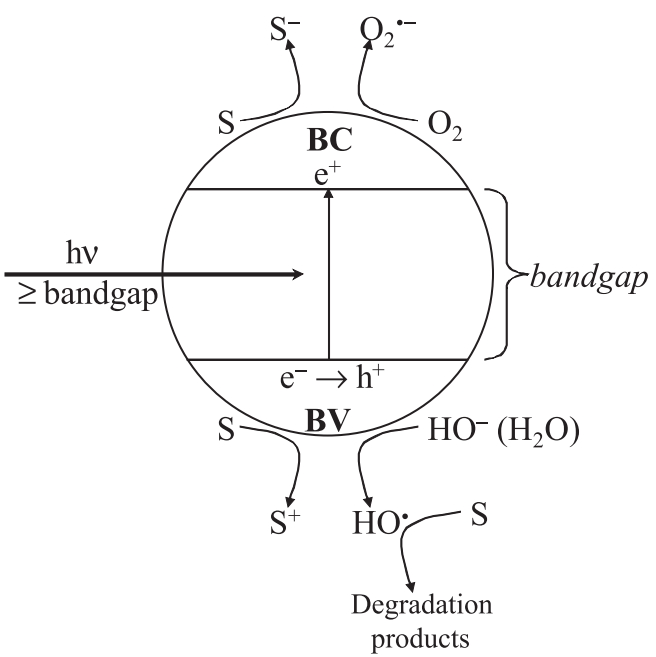

Figure 1. Diagram representing the photocatalytic process mediated by semiconductors.

Although the degradation efficiency of photocatalytic processes is extremely high, the use of semiconductors in the form of suspensions leads to serious problems of a practical nature. These problems make it difficult to develop systems for operating on a large scale. Within this context, it is possible to highlight: (i) difficulty in separating the photocatalyst, ${ }^{6}$ (ii) low quantum yield for the process, usually less than $5 \%,{ }^{6}$ and (iii) need for electron scavenger agents, usually molecular oxygen.

In order to avoid these difficulties, the use of photocatalysts immobilized in conducting supports was proposed, giving rise to photoelectrochemical processes. ${ }^{7}$ In theory, these processes are essentially photocatalytic, and are assisted by the application of an external anodic potential, which allows minimizing the electron/hole recombination process, and consequently, increases the degrading capacity of the system. ${ }^{8}$

Starting in the 60's, when DSA ${ }^{\circledR}$ (dimensionally stable anodes) electrodes were intensely used by the chlor-alkali industry, many studies have shown the potential of the photoelectrochemical process for oxidation of a wide range of substances. ${ }^{89}$ It is generally accepted that the high degradation capacity demonstrated by photoelectrochemical processes mediated by this type of electrodes is due to the superposition of two kinds of mechanisms. Firstly, the electrochemical mechanism, which involves the formation of the hydroxyl radical through the discharge of water at the conducting phase of $\mathrm{RuO}_{2}$. The second type is the photoelectrochemical mechanism, which involves heterogeneous photocatalysis processes in the semiconducting phase of $\mathrm{TiO}_{2}$, as shown in Figure 2.

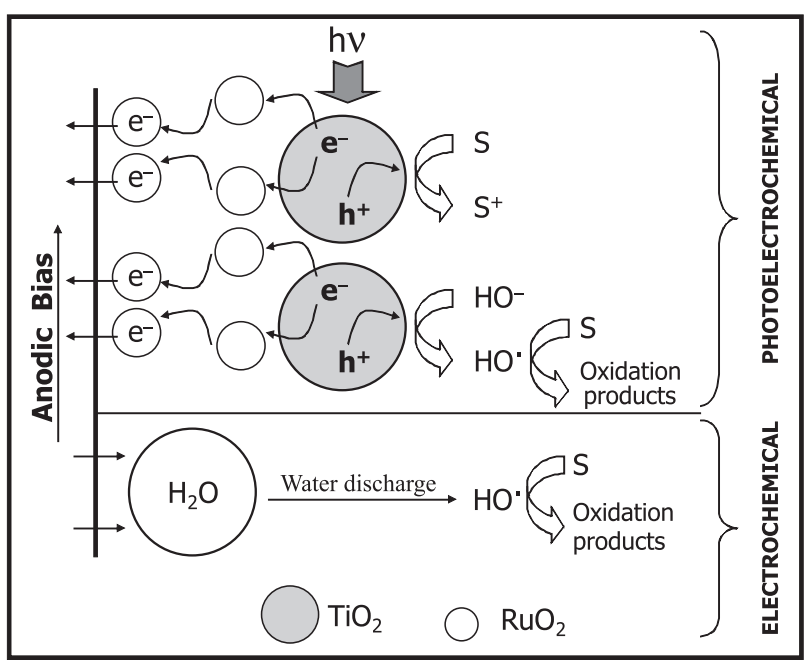

Figure 2. Diagram representing the photoelectrochemical process.

In this paper, theoretical and practical arguments are discussed, with the goal of demonstrating the actual synergy that exists between electrochemical and photochemical processes, in photoelectrochemical systems operated with DSA-type electrodes.

\section{Experimental}

\section{Reagents}

The model substrates, blue dye QR 19 (C.I. No. 61200, Aldrich), humic acid sodium salt (Aldrich) and camphor (pharmaceutical grade), were used in an aqueous solution at a concentration of $50 \mathrm{mg} \mathrm{L}^{-1}$.

\section{Photoelectrochemical treatment}

Studies were conducted in a $750 \mathrm{~mL}$ glass reactor, equipped with magnetic stirring and a water-cooled jacket. The electrodes were produced with cylindrical shape, having been arranged concentrically and separated by a distance of $1 \mathrm{~cm}$. The anode employed was a commercial electrode of the DSA type (a $138 \mathrm{~cm}^{2}$ slab of Ti/ $\mathrm{Ru}_{30} \mathrm{Ti}_{70} \mathrm{O}_{2}$ ), kindly supplied by De Nora do Brasil Ltda., while the cathode was titanium mesh, kindly supplied by Titânio do Brasil Ltda. Radiation was provided by a mercury vapor lamp $(125 \mathrm{~W})$, inserted at the center of the reactor, with the help of a quartz bulb. The current density was held constant $\left(10 \mathrm{~mA} \mathrm{~cm}^{-2}\right)$ with help from an external power 
supply (EMG 18131). A diagram representing the system is available in previous publications. ${ }^{10}$

In studies involving photolysis, light was provided only by the mercury-lamp. In the heterogenous photocatalysis process, the anode was exposed to radiation produced by the mercury-lamp, without any current flow. For the electrolysis process, the slab containing the titanium and ruthenium oxides acted as the anode and the titanium mesh as the cathode, with this system being powered by the external supply. Lastly, the photoelectrochemical processes were studied in an identical configuration, this time in association with the radiation emitted by the mercury-lamp.

In all cases, aliquots were taken at convenient times and submitted to analysis.

\section{Analytic monitoring}

The degradation of the humic acid and of the blue dye QR 19 was monitored by UV-Vis spectroscopy, using a SCINCO S1150 system. For humic acid, the degradation was expressed in terms of a ratio between the spectral area of the treated and untreated samples ( $($ rea/area $)$, integrated between 350 and $700 \mathrm{~nm}$. For the dye, the degradation was expressed by relating the absorbances $\left(\mathrm{Ab} / \mathrm{Ab}_{0}\right)$, at the maximum absorbance wavelength $(592 \mathrm{~nm})$.

The degradation of camphor was evaluated by gas chromatography (Shimadzu 14B chromatograph, flame ionization detector, DB-Wax capilary column, $30 \mathrm{~m} \times 0.25 \mathrm{~mm}, \mathrm{~J} \& \mathrm{~W}$ Scientific), after extraction in dichloromethane. The degradation was expressed in terms of a ratio between the final and initial concentrations $\left(C / C_{0}\right)$.

Measurements of total organic carbon were performed in a Shimadzu TOC-VCPH total organic carbon analyzer, based on catalytic oxidation at high temperatures and the determination of $\mathrm{CO}_{2}$ by infrared spectroscopy.

\section{Results and Discussion}

As mentioned previously, it is generally accepted that during photoelectrochemical processes, the heterogenous photocatalysis process is dominant among degradation mechanisms, and is significantly favored by the application of an external potential. In general, this collaboration is manifested in the form of an important synergistic effect, which makes it possible to degrade numerous substrates that are resistant to other degradation routines. Synergic effects of this type have been reported in the photoelectrochemical degradation of humic acid, ${ }^{9}$ using a DSA electrode, and azo dyes, using a $\mathrm{TiO}_{2}$ thin-film electrodes. ${ }^{7,11}$

According to our observations, the use of thinfilm electrodes does not contribute significantly to the photocatalytic degradation of the substrates. In the specific case of photosensitive substrates, the high rates of degradation observed can be attributed almost exclusively to the photolysis process. To illustrate this observation, Figure 3 shows a comparison between the degradation efficiency of photolysis and photocatalysis processes, involving the three model substrates used in this study. In this Figure, one clearly sees that, under our working conditions, represented by a light-intensity of $14.8 \mathrm{~mW} \mathrm{~cm} \mathrm{c}^{-2}$, the presence of the semiconductor electrode, besides not favoring the degradation process, eventually reduces the high photolysis efficiency, due to the creation of non-illuminated zones.

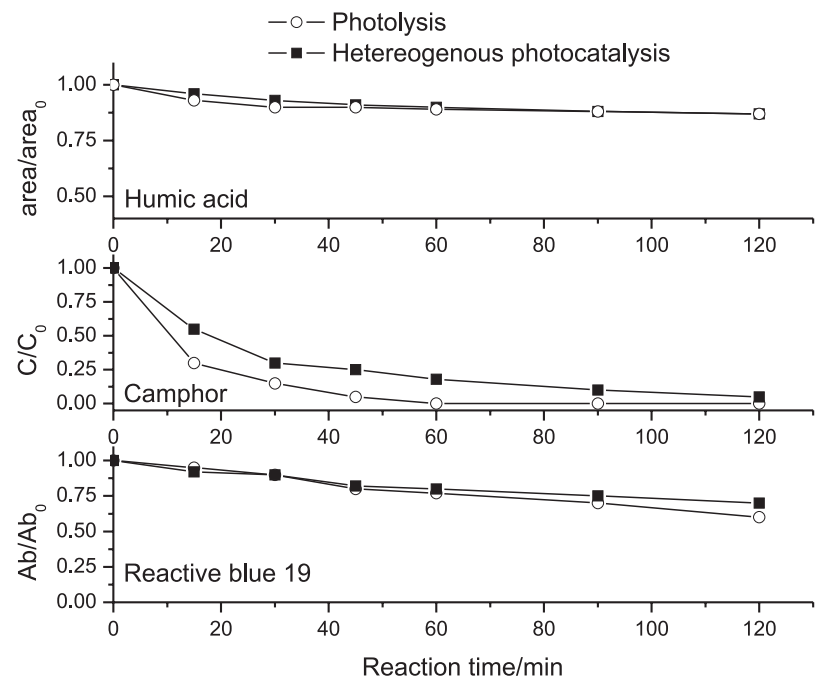

Figure 3. Comparison between photolytic and photocatalytic degradation of reactive blue 19 , camphor and humic acid, using a DSA electrode.

In recent years, reports on photoelectrochemical degradation have included studies that aim at separately measuring the contribution from photocatalysis and electrolysis processes. Unfortunately, no description is usually offered about the degradation caused by the photolysis process. Taking into consideration the photosensitivity of many substrates and the intense radiation usually employed, the photolysis process should prove to be much more relevant than what is usually considered. For instance, the spectroscopic monitoring of the degradation of reactive blue 19 by photolysis, heterogeneous photocatalysis, electrolysis and photoelectrocatalysis is shown in Figure 4.

Normally, the thickness of the semiconductor film in electrodes of the DSA type is not informed in the numerous reports involving photoelectrochemical degradation of substrates of interest. However, starting from information presented by Motheo and Pinhedo, ${ }^{12}$ it is possible to suppose that the above-mentioned photochemically active layer does not have a thickness exceeding a few micrometers. Under 


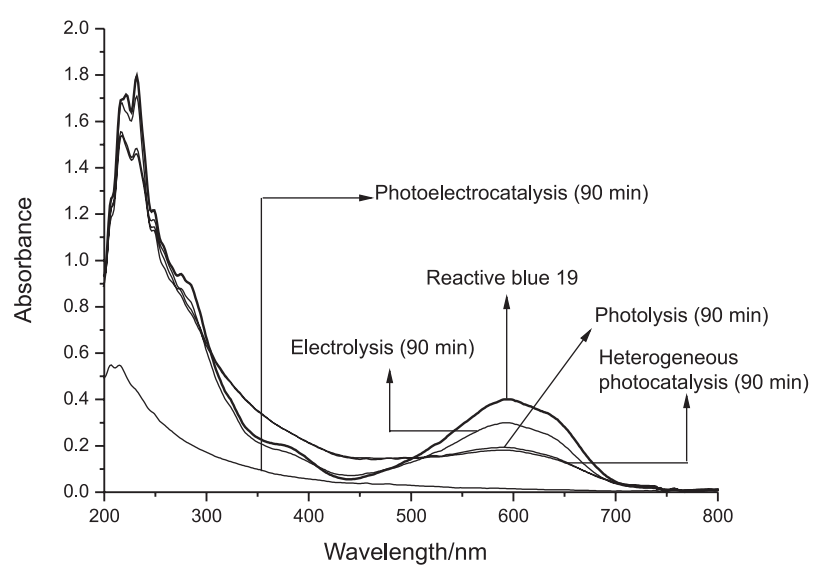

Figure 4. Spectroscopic monitoring of reactive blue 19 degradation by electrolysis, photolysis, heterogeneous photocatalysis and photoelectrocatalysis.

these conditions, the low efficiency of the photocatalytic processes is not at all surprising.

In electrochemical processes, the nature of the electrolyte plays an extremely relevant role, ensuring that the medium's ionic force is maintained and avoiding ohmic heating of the solution. In a recent study, Zainal et al. ${ }^{7}$ determine the effect of the nature of the electrolyte in the photoelectrochemical degradation of an azo dye, using an electrode made of titanium covered with a $\mathrm{TiO}_{2}$ film. According to this study, carbonate and sulphate induce losses in the efficiency of the degradation process, nitrate shows no significant effect, while sodium chloride gives rise to extremely favorable effects.

Under our experimental conditions, the presence of sodium chloride allowed nearly complete mineralization of camphor by the photoelectrochemical process, while the presence of sodium sulphate led to maximum mineralization levels on the order of $20 \%$ (Figure 5). Similar results were observed in studies involving the other model substrates.

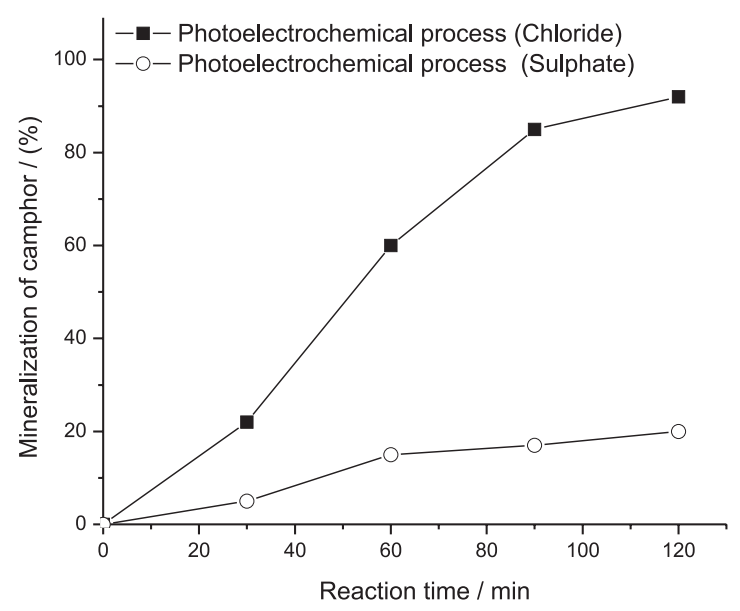

Figure 5. Effect of the support electrolyte on the photoelectrochemical mineralization of camphor.
The extreme relevance of the presence of the chloride, as well as the low photocatalytic activity displayed by the electrode, suggests that electrochemical processes are much more relevant than is generally accepted.

In a recent paper that reports the electrochemical degradation of an antraquinone dye, Rajkumar and $\mathrm{Kim}^{13}$ admit that, in the presence of chloride, electrochemical degradation arises in the "bulk" of the solution, in view of the generation of active chlorine species (see equations 1-3). This indirect mechanism is what might allow an understanding of the extreme correlation that is observed between the system's capacity for degradation and the concentration of sodium chloride in solution.

Anode: $\quad 2 \mathrm{Cl}^{-} \rightarrow \mathrm{Cl}_{2}+2 \mathrm{e}^{-}$

Cathode: $\quad 2 \mathrm{H}_{2} \mathrm{O}+2 \mathrm{e}^{-} \rightarrow \mathrm{H}_{2}+2 \mathrm{OH}^{-}$

Bulk: $\quad \mathrm{Cl}_{2}+\mathrm{H}_{2} \mathrm{O} \rightarrow \mathrm{HOCl}+\mathrm{H}^{+}+\mathrm{Cl}^{-}$

If we accept that the process in question has an electrochemical basis, mediated by oxidating agents such as molecular chlorine or hypochlorite, what remains is to understand the synergic effect arising from the applied radiation. This effect is evident when a comparison is made between the results reported by Rajkumar and $\mathrm{Kim}^{13}$ and the results of the present study. In the quoted paper, the complete degradation of several dyes is reported, using an electrochemical process analogous to the one discussed here. Mineralization, however, does not exceed the $50 \%$ level, even for very prolonged treatment times (120 min). Given that in the photoelectrochemical process mineralization of the dye reaches values exceeding $95 \%$, in reaction times of $60 \mathrm{~min}$, the effect of radiation is, as we have emphasized, quite evident.

Upon first analysis, it is possible to assume that any synergic effect arising from the incidence of radiation might be related with the generation of more energetic oxidants, made possible by photoconversion processes.

As observed by Tanaka et al., ${ }^{14}$ the half-life of a chlorine molecule is small under photolysis conditions, due to the rapid conversion into chlorine radicals (equation 4). As demonstrated in studies involving the photolytic degradation of aromatic hydrocarbons, ${ }^{15,16}$ the chlorine radical has sufficient potential for abstracting hydrogen atoms (equation 5), producing reactions that accelerate the oxidative degradation of these substrates.

Photolysis: $\quad \mathrm{Cl}_{2} \rightarrow 2 \mathrm{Cl}^{\circ}$

$$
\mathrm{Cl}^{\cdot}+\mathrm{HR} \rightarrow \mathrm{HCl}+\mathrm{R}^{\cdot}
$$


Similar reports appear in the paper by Kaczmarek et al., ${ }^{17}$ which acknowledges the important participation of the chlorine radical in photochemical processes used for the degradation of polyethylene oxide.

On the basis of the arguments discussed in this paper, I allow myself to disagree with the traditional interpretation of photoelectrochemical processes, when applied in the presence of electrodes of the DSA ${ }^{\circledR}$ type. Generally speaking, observations allow the conclusion that oxidative processes take place essentially through an indirect electrochemical path, mediated by oxidizing species such as molecular chlorine, and assisted by parallel photochemical reactions that lead to the formation of radical species with a high oxidizing power (Figure 6). In this manner, I suggest that, when applied under experimental conditions similar to the ones here described, the process traditionally called "photoelectrochemical" should be named "electrophotochemical" or, perhaps more appropriately, photochemically-assisted electrochemical process.

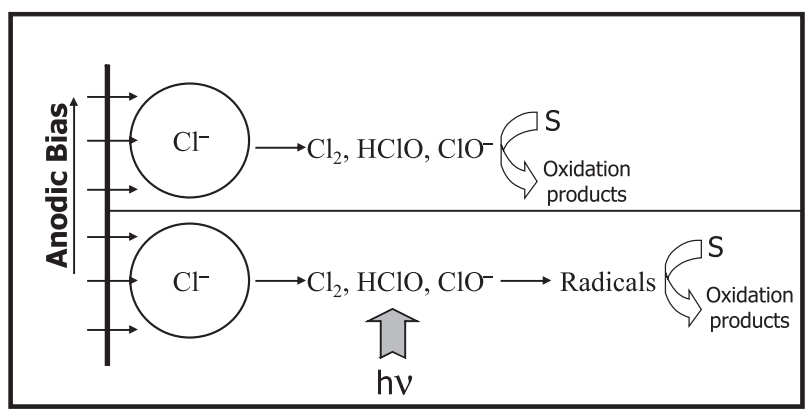

Figure 6. Diagram representing the reactions proposed for electrophotochemical degradation in the presence of active electrolytes.

\section{Conclusions}

Electrodes of the DSA ${ }^{\circledR}$ type have been massively adopted in photoelectrochemical processes used for the degradation of environmentally relevant substrates. Normally, it is accepted that heterogeneous photocatalysis is dominant in the oxidative process, and is assisted by an electrochemical component that maximizes its efficiency. The arguments presented in this paper demonstrate that, using a traditional photoelectrochemical configuration, heterogeneous photocatalysis manifests itself discretely, giving rise to results that are hard to distinguish from the effect caused by photolysis. Electrolysis, in turn, displays an efficiency that is extremely dependent on the nature and concentration of the electrolyte, which allows the determination of the relevance of indirect reactions, favored by the generation of species with a high oxidative power (molecular chlorine, for example). Under these conditions, the synergic effect of the photolytic process can be explained in terms of the generation of radical species, which also have a high oxidizing power, from chemical agents formed in a preliminary manner by electrolysis.

\section{References}

1. Bergamini, R. B. M.; Azevedo, E. B.; Raddi de Araújo, L. R. R.; Chem. Eng. J. 2009, 149, 215.

2. Devipriya, S.; Yesodharan, S.; Sol. Energy Mater. Sol. Cells 2005, 86, 309.

3. Woo, O. T.; Chung, W. K.; Wong, K. H.; Chow, A. T.; Wong, P. K.; J. Hazard. Mater. 2009, 168, 1192.

4. Fujishima, A.; Zhang, X.; Tryk, D. A.; Int. J. Hydrogen Energy 2007, 32, 2664.

5. Gaya, U. I.; Abdullah, A. H.; J. Photochem. Photobiol., C 2008, $9,1$.

6. Li, X. Z.; Li, F. B.; Fan, C. M.; Sun, Y. P.; Water Res. 2002, 36, 2215.

7. Zainal, Z.; Lee, C.Y.; Hussein, M. Z.; Kassim, A.; Yusof, N. A.; J. Hazard Mater. 2005, 118, 197.

8. Catanho, M.; Malpass, G. R. P.; Motheo, A. J.; Appl. Catal., B 2006, 62, 193.

9. Pinhedo, L.; Pelegrini, R.; Bertazzoli, R.; Motheo, A. J.; Appl. Catal., B 2005, 57, 75.

10. Tauchert, E.; Schneider, S.; Lopes de Morais, J.; PeraltaZamora, P.; Chemosphere 2006, 64, 1458.

11. Carneiro, P. A.; Osugi, M. E.; Sene, J. J.; Anderson, M. A.; Zanoni, M. V. B.; Electrochim. Acta 2004, 49, 3807.

12. Motheo, A. J.; Pinhedo, L.; Sci. Total Environ. 2000, $256,67$.

13. Rajkumar, D.; Kim, J. G.; J. Hazard Mater. 2006, 136, 203.

14. Tanaka, P. L.; Riemer, D. D.; Chang, S.; Yarwood, Y.; McDonald-Buller, E. C.; Apel, E. C.; Orlando, J. J.; Silva, P. J.; Jimenez, J. L.; Canagaratna, M. R.; Neece, J. M.; Mullins, C. B.; Allen, D. T.; Atmos. Environ. 2003, 37, 1393.

15. Lewandowski, M.; Ollis, D. F.; J. Catal. 2003, 217, 38.

16. Han, D. H.; Stuchinskaya, T.; Won, Y. S.; Park, W. S.; Lim, J. K.; Radiat. Phys. Chem. 2003, 67, 51.

17. Kaczmarek, H.; Sionkowska, A.; Kaminska, A.; Kowalonek, J.; Swiatek, M.; Szalla, A.; Polym. Degrad. Stab. 2001, 73, 437.

Submitted: September 14, 2009 Published online: May 7, 2010 